\title{
Fatigue damage evaluation on austenitic stainless steel using nonlinear ultrasonic method
}

\author{
zhenhua Chen ${ }^{1}$, Guocheng $\mathrm{Xu}^{1}$, Wei $\mathrm{Lu}^{2}$, Weibing $\mathrm{Chen}^{1}$, and Zhenhua Chen ${ }^{3}$ \\ ${ }^{1}$ Nanchang Hangkong University - Qianhu Campus \\ 2 AVIC Manufacturing Technology Institute \\ ${ }^{3}$ Gannan Normal University
}

October 27, 2020

\begin{abstract}
The closed crack and micro damage are liable to be underestimated in conventional (linear) ultrasonic nondestructive testing, which lead to unpredictable safety hazards. The objective of this work was to detect the fatigue damage in the stainless steel samples by use of nonlinear ultrasonic method. In the first, the macro cracks of fatigue specimens were measured by metallographic method. Secondly, the finite amplitude method of nonlinear ultrasonic testing was employed to evaluate the micro damages, and both the linear and the nonlinear characteristics of testing signals were investigated. Thirdly, the influences of excitation voltage on the finite amplitude method were discussed. The results indicate that the maximum value of the relative nonlinearity parameter is sensitive to the closed cracks and micro damages which are unable to be detected by the amplitude of linear ultrasonic testing. Higher excitation voltage is beneficial for exciting the nonlinear response of closed crack, which can be used to evaluate the degree of fatigue damage.
\end{abstract}

\section{Hosted file}

Fatigue damage evaluation on austenitic stainless steel using nonlinear ultrasonic method.pdf available at https://authorea.com/users/370453/articles/489111-fatigue-damage-evaluation-onaustenitic-stainless-steel-using-nonlinear-ultrasonic-method

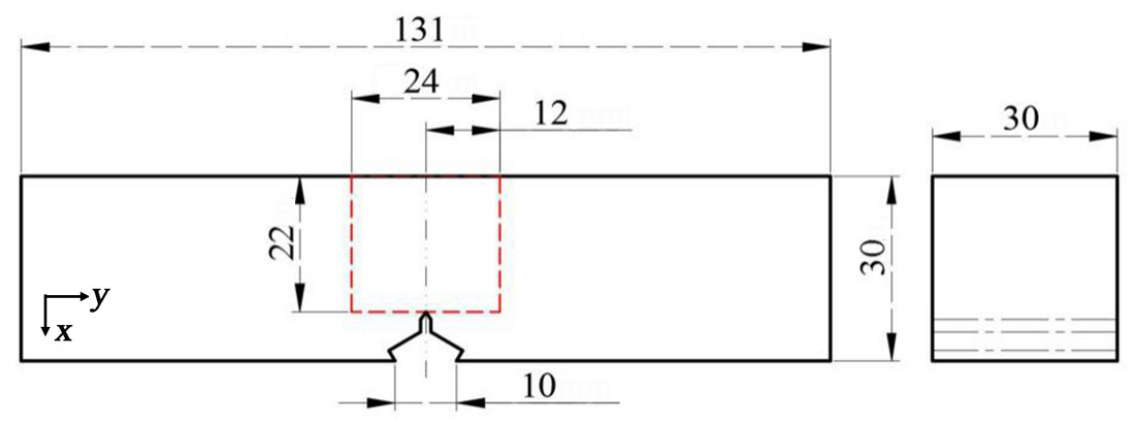




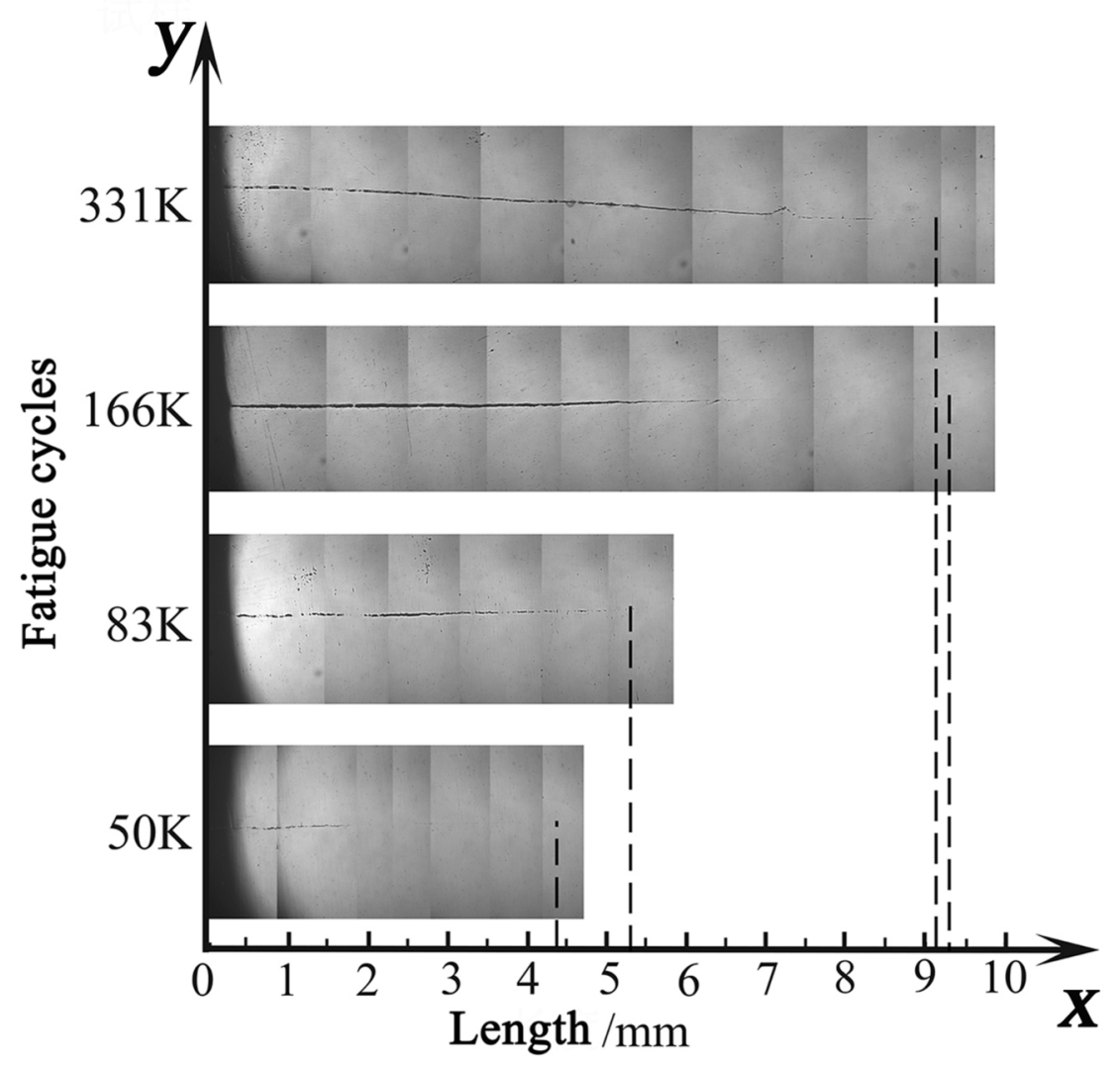



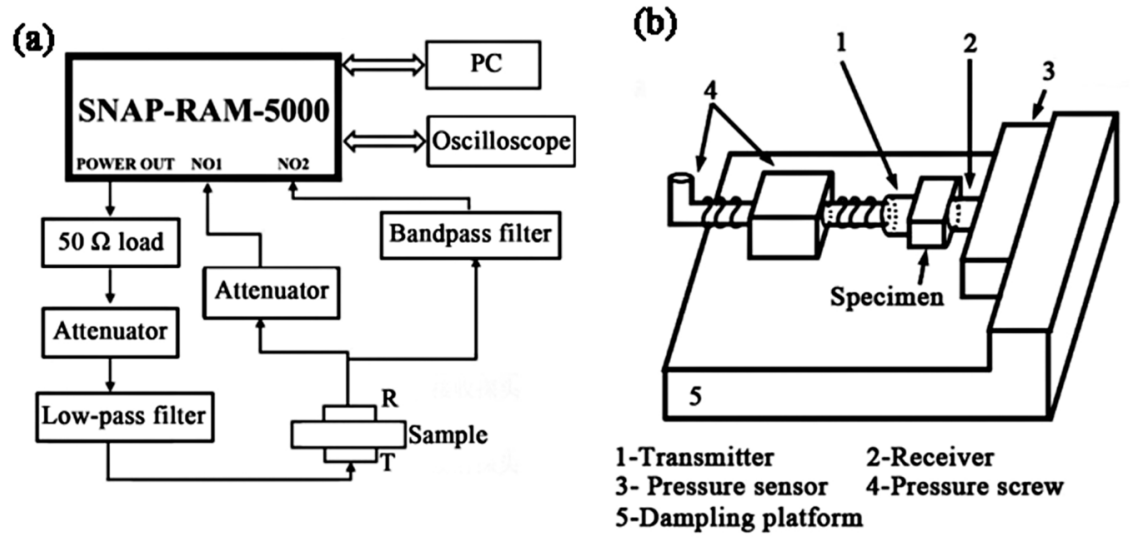

(c)

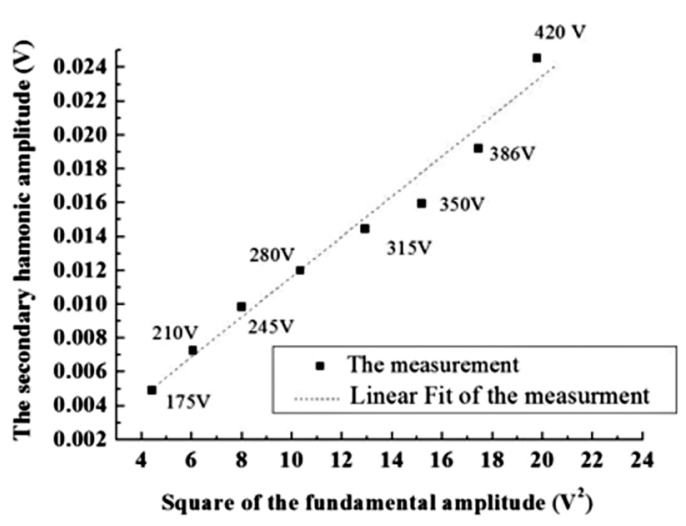




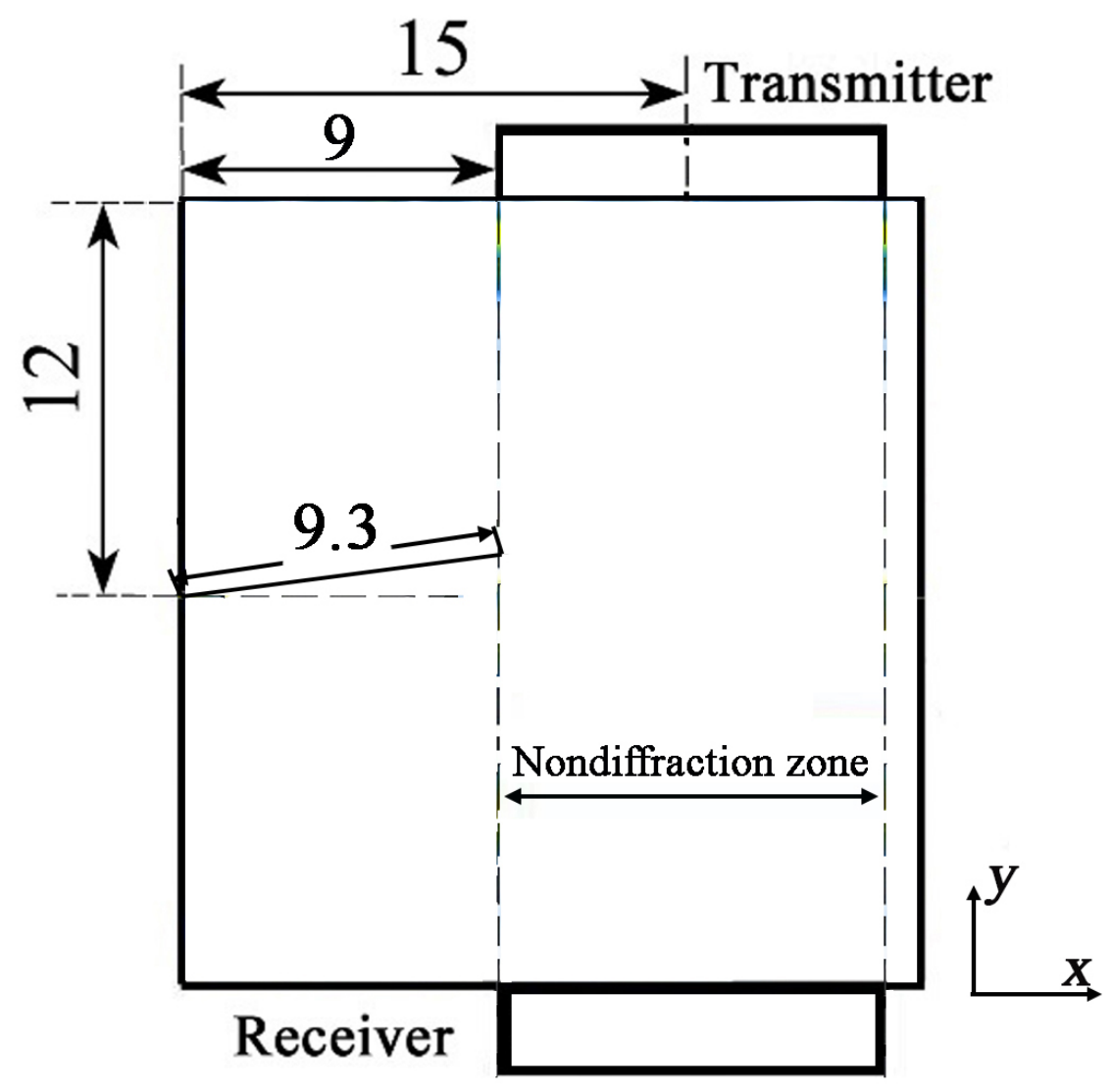



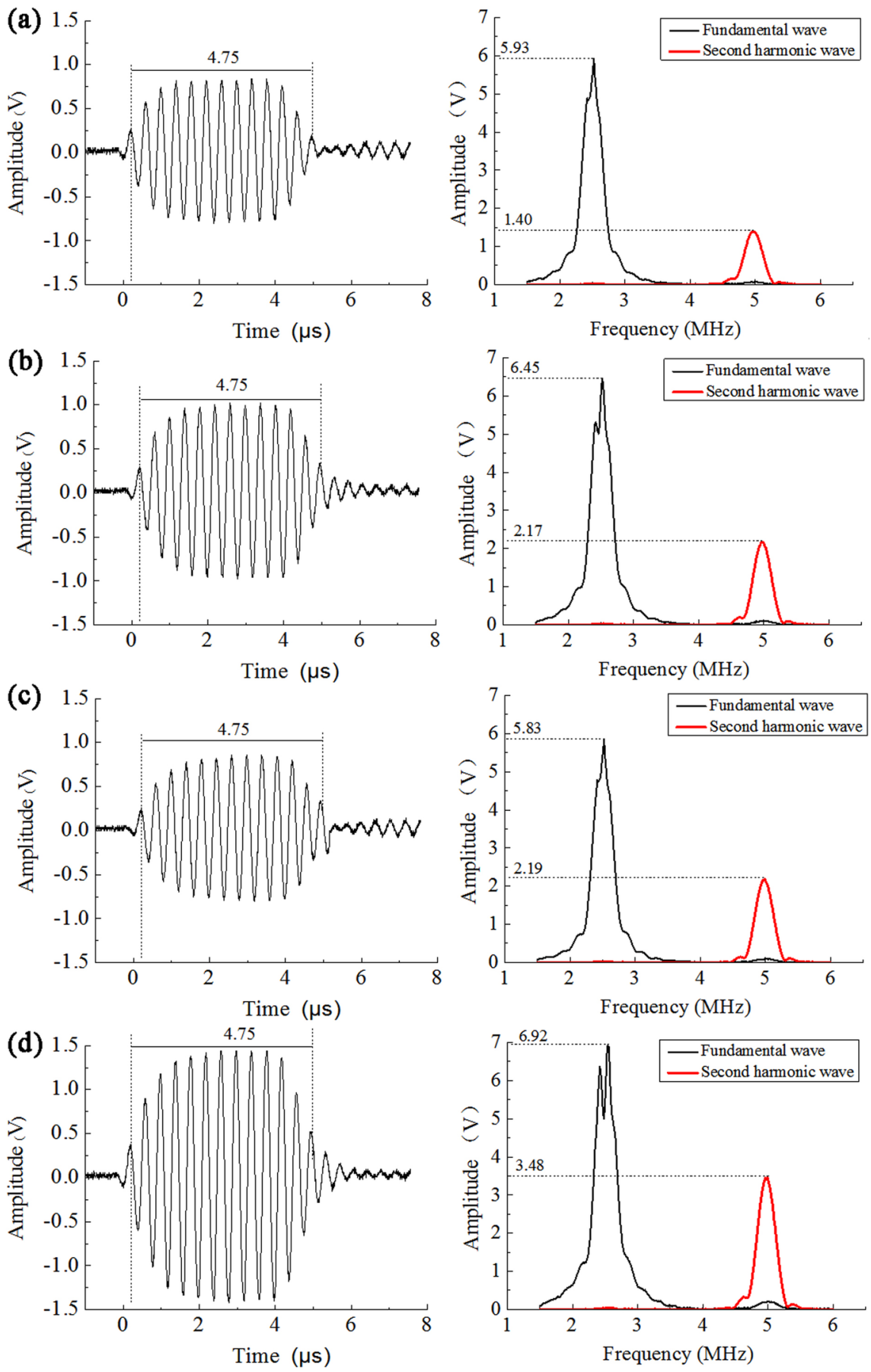

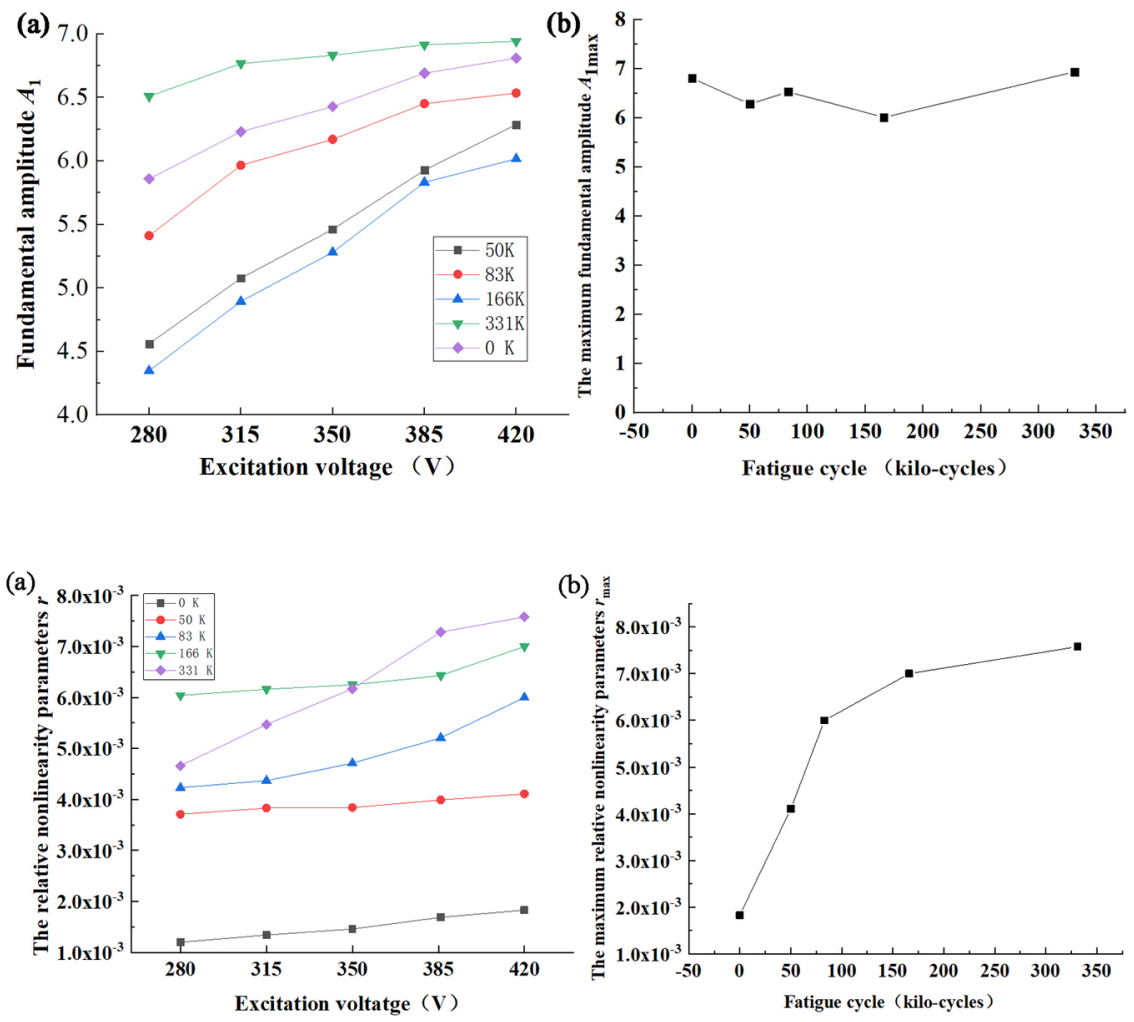

(b)

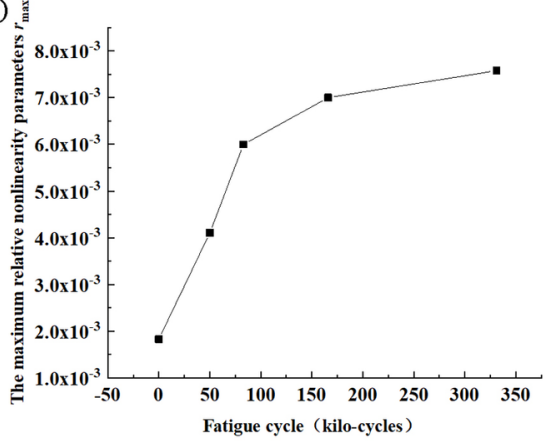

